\title{
Commercial delivery of genetic improvement to conifer plantations using somatic embryogenesis
}

\author{
Ben Sutton* \\ CellFor Inc., Suite 408, 355 Burrard Street, Vancouver, BC V6C 2G8, Canada
}

(Received 16 August 2001; accepted 18 March 2002)

\begin{abstract}
Somatic embryogenesis of conifers has been the subject of intensive research by a number of organizations over the last 15 years. The maintenance, cryopreservation and production of embryos from embryogenic cultures of individual trees have been demonstrated for several commercial species. These attributes have enabled CellFor Inc. (a commercial provider) to develop and deploy over 4500 clones in field tests. It is expected that selection of elite clones from such tests will result in gains of more than $40 \%$ in volume growth over population means. While individual elite parent trees may exhibit improvements in excess of $25 \%$, seed orchards typically yield less than half this gain operationally. Hence the ability to deploy selected clones of elite families through mass production of somatic embryos has significant value. CellFor has developed a bulk embryo production and sowing methods to achieve this, with initial volumes of 2 million somatic seedlings annually.
\end{abstract}

somatic / embryogenesis / conifer / clonal / forestry

Résumé - Retombée commerciale de l'amélioration génétique des plantations résineuses par embryogénie somatique. Au cours des 15 dernières années, l'embryogenèse somatique chez les résineux a été l'objet de recherches intensives par un grand nombre d'organisations. La conservation, la cryo-conservation et la production d'embryons à partir de cultures embryogéniques d'arbres individuels ont été bien établies pour plusieurs espèces commerciales. Ces attributs ont permis à CellFor Inc. (un producteur commercial) le développement et la mise en place de plus de 4500 clones dans des expérimentations au champ. Il est espéré que la sélection de clones élites à partir de tels tests produira un gain d'accroissement en volume de plus de $40 \%$ par rapport aux moyennes des populations. Alors que les arbres élites parents peuvent, individuellement, présenter une amélioration de plus de $25 \%$, la production des vergers à graines, généralement, est pratiquement moins que la moitié encore de ce gain. Désormais, la possibilité de produire des clones, sélectionnés à partir de familles d'élite en employant une production de masse d'embryons somatiques, a une valeur significative. CellFor a développé avec des méthodes de semis une production industrielle d'embryons qui atteint un volume initial annuel de 2 millions de semis somatiques.

somatique / embryogenèse / résineux / forêt

\section{INTRODUCTION}

Clonal forestry offers very significant advantages for forest productivity due to the genetic gain (volume and quality improvements) which can be realized through selection and mass propagation of elite individuals (clones). In addition, efficiencies in forest management and end product utilization may also be achieved. These benefits are already being realized in some hardwood species but not as yet to a significant extent in coniferous species. The principal limitation in conifers is the phenomenon of physiological maturation (or aging) which, while poorly understood, prevents sustained clonal propagation through cuttings, due to (a) decreased rooting and (b) increasing occurrences of plagiotrophic growth problems as the donor plants age. In some cases these limitations occur in hardwood (angiosperm) species but are more typical in temperate conifer species including the principal commercial forestry species. The establishment of embryogenic cultures that are capable of both long-term

* Correspondence and reprints

Tel.: (604) 602 9229; fax: (604) 683 6859; e-mail: bsutton@ @ellfor.com 
frozen storage and sustained embryo production has effectively overcome these limitations.

Somatic embryogenesis (SE) of conifers has been extensively reviewed in the scientific literature (see recent review by Cyr [5]). By 1998 there were published reports of somatic embryogenesis in 43 conifer species and hybrids covering the genera Abies (fir), Larix (larch), Picea (spruce), Pinus (pine) and Pseudotsuga (Douglas-fir) represented in the family Pinaceae. There are other isolated reports for the family Cupressaceae represented by Chamaecyparis (cypress), Cupressus (cedar) and Juniperus (juniper); and family Taxodiaceae is represented by Sequoia (sequoia). One report of SE for family Araucariaceae has been issued (Araucaria). The steps commonly reported include removing embryos from elite seed (usually resulting from controlled pollination) and placing them on a culture medium to induce formation of an embryogenic culture. Embryogenic cultures can be stored in cryopreservation or used for the production of mature somatic embryos. Germination of the embryos is typically carried out in vitro for a period of 6-14 weeks before the resulting plants are transferred to soil.

SE technology, as practiced to date, offers the potential for storage and testing of clones as well as production of limited numbers of plants. However, considerably greater production rates and large-scale handling systems are required in order to use SE for mass production of somatic seedlings for operational deployment. While it is possible to use small numbers of somatic seedlings as mother plants for cuttings production, the speed and logistical advantages of mass production offer much greater potential. CellFor Inc. is a commercial company engaged in the development, testing and mass production of superior conifer clones using SE. This paper outlines the benefits and value of SE in clonal forestry as well as CellFor's SE production technology.

\section{SOMATIC EMBRYOGENESIS DEVELOPMENTS}

Effective commercial use of embryogenesis has necessitated a number of key technical developments, which can be summarized as follows:

Table I. Summary of new technologies developed by CellFor Inc. for somatic embryogenesis production.

\begin{tabular}{ll}
\hline Technology & Purpose \\
\hline $\begin{array}{l}\text { Increasing ABA and water } \\
\text { stress during maturation }\end{array}$ & $\begin{array}{l}\text { Development of high quality embryos at high } \\
\text { frequency } \\
\text { Desiccation tolerant } \\
\text { embryos }\end{array}$ \\
$\begin{array}{l}\text { Embryos can be dried to allow storage } \\
\text { of inventory }\end{array}$ \\
germination & $\begin{array}{l}\text { Enables the use of existing nursery technology, } \\
\text { facilities and practices for production of somatic } \\
\text { seedlings (eliminates the need for sterile culture } \\
\text { rooms for germination) }\end{array}$ \\
\hline
\end{tabular}

The technical basis for these developments is explained below.

\subsection{Improvements in embryo performance and germination}

Considerable work has been directed towards the improvement of somatic embryo development in vitro. The goal of this work has been to maximize the number of embryos produced and to enhance their quality. The key aspects of quality considered are the ability to survive desiccation and the ability to germinate vigorously. The importance of both abscisic acid (ABA) and water stress in increasing embryo yield and promoting embryo development have been described previously $[2,3]$. This work demonstrated that raising both ABA and water stress are beneficial to embryo quality, as they prevent precocious germination and promote full morphological development and accumulation of storage reserves. However, application of high levels of these agents throughout maturation tends to limit the number of embryos that develop. Further developments have resulted in a method which involves manipulating both $\mathrm{ABA}$ and water stress throughout maturation in order to effect the optimum productivity and embryo quality [1].

In the context of mass production, the yield of embryos and their success in germination and conversion to somatic seedlings are clearly of critical importance. Moreover, in order to coordinate mass production with delivery to forestry nurseries, the ability to dry and store the embryos is critical. Storage allows continuous embryo production and the accumulation of sufficient inventory for delivery of large numbers of embryos to nurseries to meet seasonal sowing demands. This is particularly critical when one considers that seed for many millions of seedlings is typically sown in forest nurseries within a three-week time frame, most often at one specific time of year.

\subsection{Mass production and sowing of embryos}

The effective maturation of embryos requires that $\mathrm{ABA}$ and water stress are increased throughout the maturation process. The precise control of these variables can be achieved efficiently using liquid medium supplied to developing embryos in bioreactors [4]. The commercial benefits of bioreactors include scalability and significant savings associated with preparation of liquid medium as opposed to solidified medium.

To date, somatic embryos have commonly been germinated in vitro on agar medium containing sucrose, amino acids and basal salts. To be effective, supplementary light and temperature control are also required. Furthermore, embryos are usually selected from the maturation stage and placed in the in vitro containers individually by hand. These labour-intensive steps represent a large portion of the cost of producing somatic seedlings and also they are not feasible to conduct at scale from a logistical perspective. In order to overcome these limitations CellFor has developed systems 

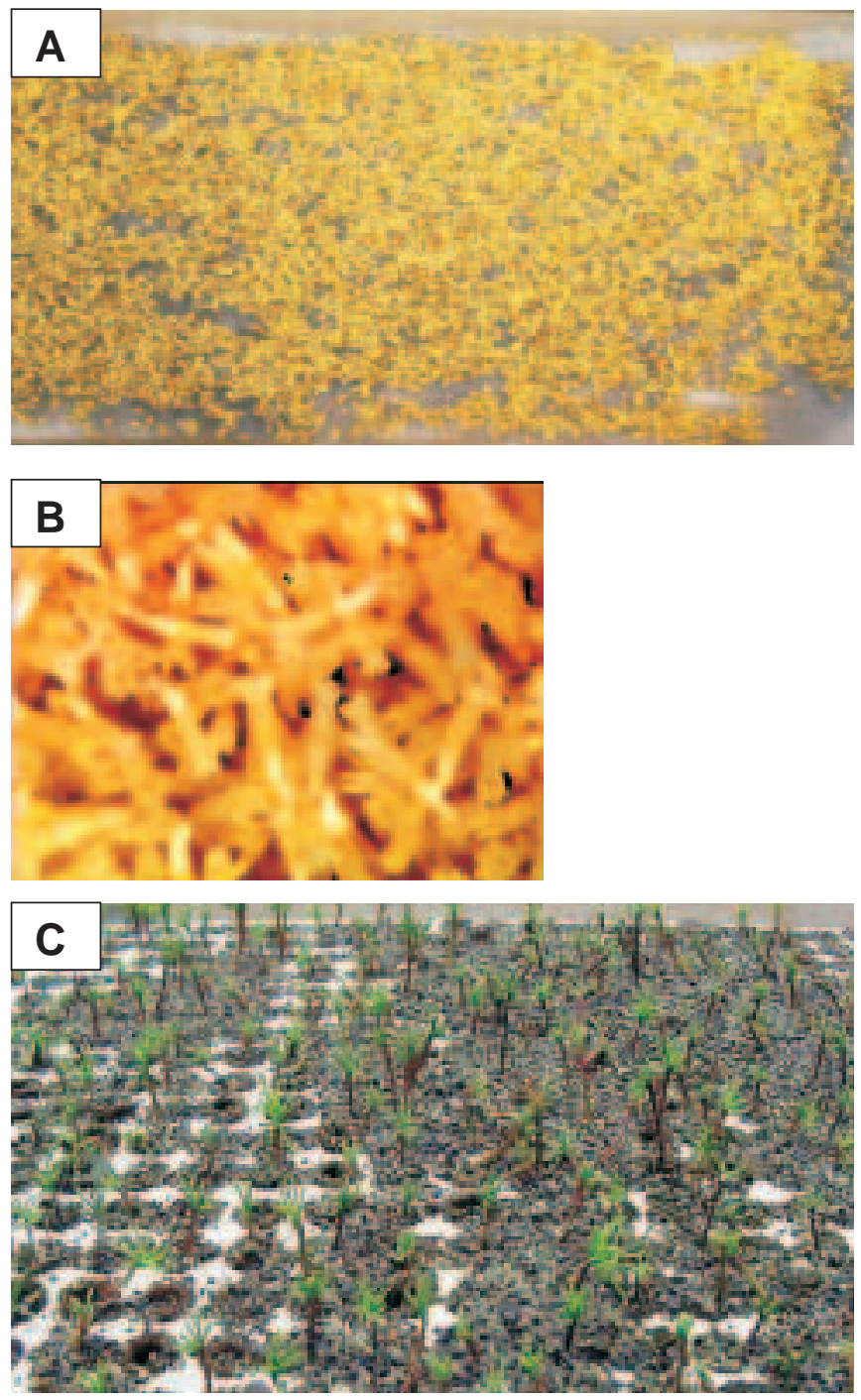

Figure 1. Mass production and sowing of embryos. A. Somatic embryos during maturation in bioreactor; B. embryos following purification and drying; C. germination ex vitro, 7 days after sowing.

for bulk harvesting and purification of embryos from bioreactors as well as for germination of embryos in nursery environments (figure 1). The latter involves the treatment and machine-sowing of the embryo into small containers (miniplugs) containing commercial growing mixes. These treatments result in rapid germination and early growth of the somatic seedlings.

\subsection{Miniplug production}

CellFor has employed miniplugs to grow very small somatic seedlings which can be produced at very high density (ca. $3500 \mathrm{~m}^{-2}$ ) within 6 to 8 weeks following sowing. Miniplugs can be shipped in large numbers at low cost and can also be machine transplanted to full size forest seedling

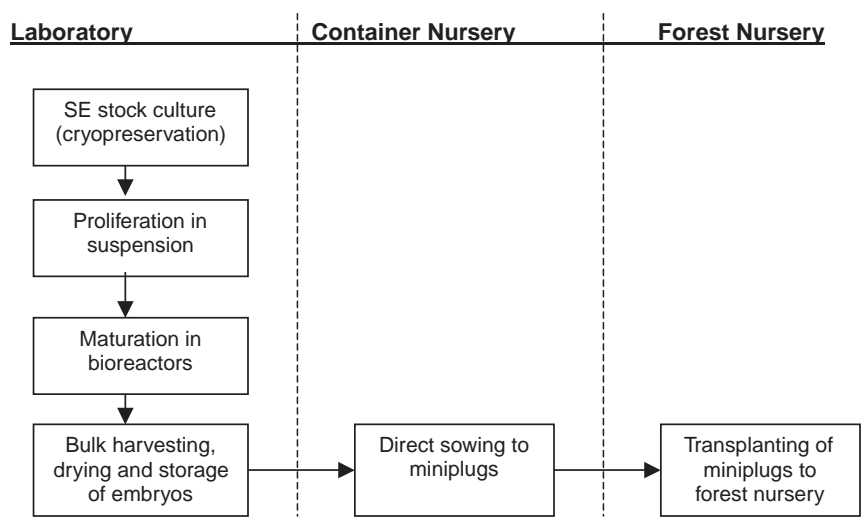

Figure 2. Overview of CellFor's commercial production system.

containers or bare root nurseries to complete seedling development prior to field planting. Machines for both types of transplanting operation have been purchased and adapted successfully. In view of these features, CellFor has adopted the miniplug as a first commercial product. In future it is expected that the required technology will be transferred to customer nurseries. This will enable embryos to be shipped conveniently worldwide from a centralized production facility (figure 2).

\section{APPLICATION OF SE TO DELIVERY OF GENETIC IMPROVEMENT}

\subsection{Deployment of improved seed and clonal forestry}

The most widely used method for operational production of improved seed has been open-pollinated seed orchards. The principal advantage of this approach has been the comparatively low cost of production. It has been assumed that seed orchards provide seed with a genetic value equal to the mean of the parents within the orchard. In practice, the genetic gain achieved is substantially lower than this because of pollen contamination and unequal pollen and seed contributions by the parental clones in the seed orchard $[6,7]$.

In view of these limitations many organizations have initiated programs to produce control-pollinated seed. This allows specific crosses to be made between individuals of known genetic value assuring higher levels of genetic gain. However, the production of control-pollinated seed is expensive and it is logistically challenging to obtain sufficient seed for a large scale planting program. Regardless of the method used, seven to ten years are typically required to obtain sufficient seed production in an orchard. This means that the deployment of improvements identified through genetic testing is substantially delayed. The use of somatic embryogenesis allows the establishment of embryogenic clones capable of mass production from relatively small quantities of 


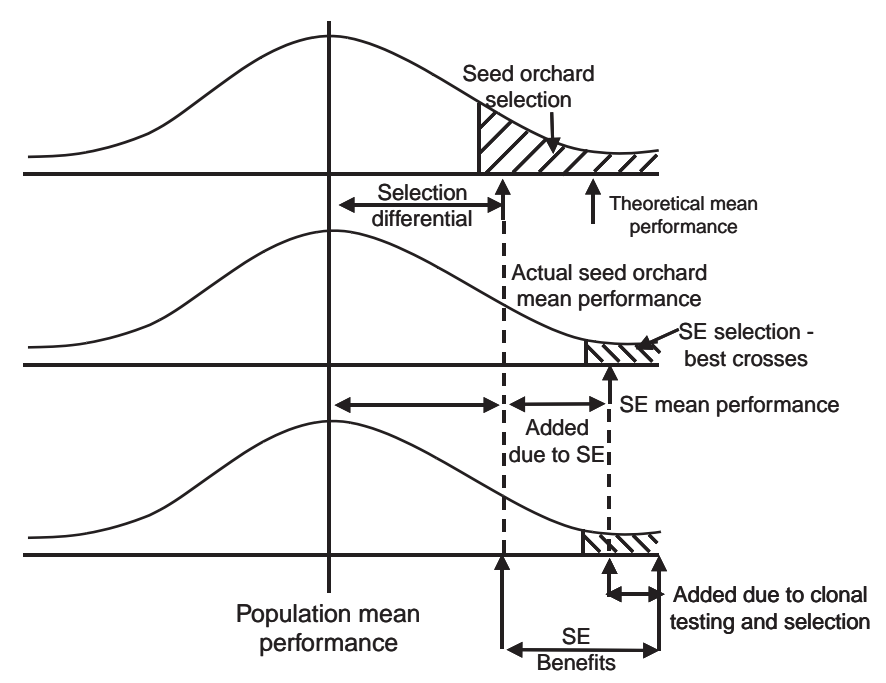

Figure 3. The application of somatic embryogenesis to selection and mass production of clones from elite seed families.

control-pollinated seed. Thus the operational deployment of seedlings from newly selected individuals could be achieved without the cost and time delay required to establish a seed orchard. In addition, once established the clones can be tested to select for additional improvement based on within family variation (figure 3).

Elite parental populations exhibiting volume gains in excess of $25 \%$ over the base population are often available and improvements in form wood quality and pest resistance have also been made. Pollen contamination and imbalances in gametic contributions in open pollinated loblolly pine seed orchards in the S. East US, for example, are expected to reduce the actual level of gain to $8-13 \%$ in volume. Selection and crossing of the top parents leads to genetic gains in volume in the order of $30 \%$ [8]. Further selection within families (clonal selection) is expected to yield gains in excess of $40 \%$ in volume, together with further improvements in disease resistance, form and wood quality. The use of clones also offers significant opportunities for the deployment and harvesting of pure clonal blocks with desired uniform characteristics. The overall benefits of deployment through embryogenesis versus open pollinated seed orchards are summarized below:

Table II. Examples of potential benefits of somatic embryogenesis.

\begin{tabular}{ll}
\hline Open pollinated seed orchards & Clonal forestry using SE \\
\hline 13\% genetic gain & $40-60 \%$ genetic gain \\
Trees variable & Trees uniform \\
Variable wood quality & Selected wood quality \\
Deployment of next generation & Deployment of next generation \\
in 12 years & in 1.5 years \\
\hline
\end{tabular}

\subsection{Establishment and testing of clones}

A number of organizations have engaged in the establishment of large numbers of clones and the production of small numbers of plants for the purposes of clonal tests. Such clonal tests are an important pre-requisite for the mass production of elite clones with known performance. In order to carry out a clonal selection program, an appropriate design is made considering the elite trees to be used as parents for control pollinated families, the number of seed required to yield an appropriate number of embryogenic clones per family and the final number of clones to be selected. The intensity of selection is a key criterion in determining the total number of clones to be tested and the potential genetic gain that can be achieved. In addition, the eventual deployment population must consist of an appropriate number of unrelated clones to yield appropriate genetic diversity (see following section). A number of programs have been initiated with the aim of testing 500 to 1000 clones from 10 to 30 crosses. Typically desired levels of genetic improvement (relative to the investment in the program) require that selection of the top performing 5\% or less of the clones are selected [10]. CellFor Inc. has engaged in such clonal testing programs over the last 8 years and has now deployed plants from over 4500 clones (table III).

Table III. Summary of clonal trials in process using embryogenic clones.

\begin{tabular}{lccc}
\hline Species & $\begin{array}{c}\text { \# of Clones in } \\
\text { field to 2000 }\end{array}$ & $\begin{array}{c}\text { \# of Clones } \\
\text { (2001 planting) }\end{array}$ & Total \\
\hline Loblolly/slash pine & 170 & 420 & 590 \\
Radiata pine & 753 & 1200 & 1953 \\
Spruce* & 1900 & - & 1900 \\
Douglas-fir & 3 & 72 & 75 \\
Total & $\mathbf{2 ~ 8 2 6}$ & $\mathbf{1 6 9 2}$ & $\mathbf{4 5 1 8}$ \\
\hline
\end{tabular}

* Including interior spruce species (predominantly white spruce) and Sitka spruce.

While precise selection of top performing clones may take 4 to 7 years, in most conifer species initial selections prior to that are likely to result in a significant improvement in productivity. Furthermore, the ability to cryopreserve embryogenic clones enables alternate clones to be brought into production if revisions are made in the initial selections. Hence, the clone banks that have been established to date serve as the basis for commercial production of clones which will perform better than the family means in the near future.

\section{OUTLOOK FOR LARGE-SCALE DEPLOYMENT OF CLONES USING SOMATIC EMBRYOGENESIS}

Advances in vegetative propagation methods have provided tree breeders with a range of options whereby the gains attained from tree improvement programs can be quickly 
achieved. However, the inverse relationship between genetic gain and genetic diversity requires a method to attain a reasonable balance between the two in order to reap the rewards of selection without risking loss due to reduced genetic diversity. When maximum genetic gain is achieved by using the single best genotype for deployment, genetic diversity is minimised. Conversely, maximum genetic diversity can be achieved by deploying a very large number of genotypes; however, genetic gain is then minimal.

The concept of risk versus gain poses a dilemma for breeding and selection programs. Libby [9] first addressed this dilemma as he investigated the number of clones to use in a plantation with minimum risk. He concluded that single clone plantations are often the best strategy, mixtures of two or three clones are often the worst, and mixtures of large number of clones (7-25) are as safe as "family" or "natural population" seedling plantations. Subsequent theoretical analysis by a number of other workers has generally lead to the conclusion that a maximum of 20-40 clones would lead to equivalent or better protection against catastrophic loss than a larger number of clones. This general consensus is reflected in the operating principles commonly employed by organisations practising clonal forestry with hardwood species. In eucalyptus plantations an upper limit of $5 \%$ of the plantation area for deployment of single clone is common.

CellFor is likely to follow the guidelines laid down by its customers for the level of genetic diversity that is desired. Following these guidelines it is possible to optimise the level of genetic gain which is achieved by fine tuning the mix of families and clones within family which are allocated to the production population.

CellFor is producing approximately 2 million somatic seedlings annually from elite control-pollinated families of loblolly pine and Douglas fir. Progressive selection based on data from clonal trials will result in steady improvement in performance beyond the mean of these elite families.

In summary, a scalable commercial production system for the delivery of elite conifer clones is now in place. Furthermore, there is ample precedence to suggest that clones can be deployed in a manner that ensures very significant genetic gain while managing risk appropriately. In order for this to become a reality in a commercial context sufficient value must be realised to support the costs of production and of continued technology development. The present value of gains in productivity (examples as outlined in this paper) will depend on a multiplicity of factors including inherent growth rate, ro- tation age, site productivity, log prices, interest rates, tax structure and so on. However, present values in the order of $\$ 1000$ to $\$ 2000$ per hectare are reasonable for faster growing species, based on growth and yield models and financial analysis. The average number of seedlings planted per hectare is approximately 1200 , although this varies considerably by region and management regime. These incremental values are certainly adequate to support the costs of an effective SE production system.

Acknowledgements: This paper is intended to be a summary of the commercial status of somatic embryogenesis technology, specifically as it relates to CellFor's experience. I am indebted to my many co-workers for providing the basis for such a summary including, Steve Attree, Sheila Binnie, David Cyr, Yousry El-Kassaby, Dan Polonenko and also to various collaborators over the years, most especially Krystyna Klimaszewska of the Canadian Forest Service.

\section{REFERENCES}

[1] Attree S.M., Increasing levels of growth regulator and/or water stress during embryo development, PCT Application [PCT/CA/99/00524], 2000.

[2] Attree S.M., Fowke L.C., Embryogenesis of gymnosperms: advances in synthetic seed technology of conifers, Plant Cell Tissue Organ Cult. 35 (1993) 1-35.

[3] Attree S.M., Moore D., Sawhney V.K., Fowke L.C., Enhanced maturation and desiccation tolerance of white spruce [Picea glauca (Moench) Voss] somatic embryos: Effects of a non-plasmolysing water stress and abscisic acid, Ann. Bot. 68 (1991) 519-525.

[4] Attree S.M., Pomeroy M.K., Fowke L.C., Production of vigorous, desiccation tolerant white spruce (Picea glauca-Moench. Voss.) synthetic seeds in a bioreactor, Plant Cell Rep.13 (1994) 601-606.

[5] Cyr D.R., Part 3: Enhancing Seed Performance 10. Seed substitutes from the laboratory, in: Black M., Bewley J.D. (Eds), Seed Technology and its Biological Basis, Sheffield Academic Press (CRC Press LLC), Sheffield, UK, 2000, pp. 326-372.

[6] El-Kassaby Y.A., Genetics of seed orchards: expectations and realities, in: Proc. of the 20th South. For. Tree Improve. Conf., June, 1989, Charleston, South Carolina, USA, 1989, pp. 87-109.

[7] Friedman S.T., Adams W.T., Estimation of gene flow into two seed orchards of loblolly pine (Pinus taeda L.), Theor. Appl. Genet. 69 (1985) 609-615.

[8] Li B., McKeand S., Weir R., Tree Improvement and sustainable forestry - impact of two cycles of loblolly pine breeding in the USA, Forest Genetics 6 (4) (1999) 229-234.

[9] Libby W.J., What is a safe number of clones per population?, in: Heybroek H.M., Stephan B.R., von Weissenberg K. (Eds.), Resistance to Disease and Pests in Forest Trees, Proc. IUFRO Third International Workshop on the Genetics of Host-Parasite Interaction in Forestry, Wageningen, The Netherlands, 1982 , pp. $342-360$.

[10] Sutton B.C.S., Grossnickle S.C., Roberts D.R., Russell J.H., Kiss G.K., Somatic embryogenesis and tree improvement in interior spruce, J. For. 91 (1993) 34-38. 
